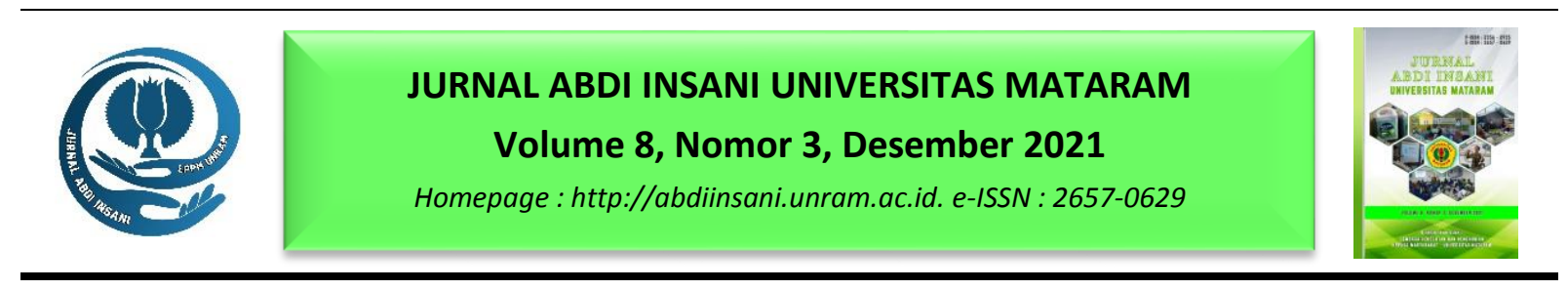

\title{
PENGENALAN DASAR-DASAR PERENCANAAN INSTALASI PROTEKSI PETIR PADA GEDUNG BERTINGKAT DI SMAN 8 MATARAM
}

\section{Introduction to the Basics of Lightning Protection Installation Planning on Store Building at SMAN 8 Mataram}

\author{
Ni Made Seniari ${ }^{1 *}$, Supriyatna ${ }^{1}$, Abdul Natsir $^{1}$, Ida Ayu Sri Adnyani ${ }^{1}$, Sabar Nababan ${ }^{1}$, \\ Bagus Widhi Dharma² \\ ${ }^{1} J u r u s a n$ Teknik Elektro Universitas Mataram, ${ }^{2}$ Jurusan Teknik Sipil Universitas Qamarul \\ Huda Badaruddin Bagu
}

Jl. Majapahit 62, Mataram 83125, Nusa Tenggara Barat, Indonesia

Alamat korespondensi : seniari_nimade@unram.ac.id

(Tanggal Submission: 5 Desember 2021, Tanggal Accepted : 31 Desember 2021)

\begin{abstract}
Kata Kunci : Abstrak :
Pengenalan Proteksi petir pada gedung bertujuan untuk melindungi gedung beserta instalasi isinya, serta melindungi objek di sekitar titik sambaran. Proteksi petir ini telah proteksi petir diatur dalam Undang-Undang No. 28 Tahun 2002 dan peraturan pemerintah No. 36 Tahun 2005. Untuk mendapatkan perlindungan yang optimal, perlu perencanaan pemasangan instalasi petir yang tepat. Keterampilan perencanaan instalasi proteksi petir pada gedung bertingkat adalah materi keterampilan khusus yang tidak terdapat dalam kurikulum. Tujuan kegiatan ini adalah memberikan keterampilan tambahan kepada Siswa SMA, sehinga siswa memiliki pengetahuan dan keterampilan praktis yang berpotensi untuk membuka lapangan kerja mandiri. Metode kegiatan dengan ceramah tentang tahapan perencanaan pemasangan instalasi proteksi petir, membahas dan mengaplikasikan materi SNI-03-7015- 2004. Dalam ceramah diselingi dengan peragaan pemasangan instalasi dan memutar video-vidio terkait. Perencanaan instalasi diawali dengan ukuran bangunan, bentuk atap dan karakteristik petir daerah setempat. Secara berkelompok, siswa dilatih merencanakan instalasi petir suatu bangunan dengan dimensi dan bentuk yang beragam. Hasil kegiatan, siswa mendapatkan pengetahuan dasar dan keterampilan tambahan perencanaan instalasi system proteksi petir, yang bisa dikembangkan secara mandiri. Keberhasilan kegiatan secara kuantitatif menunjukkan peningkatan pengetahuan siswa sebesar $70,74 \%$.
\end{abstract}

Panduan sitasi / Citation guidance (APPA $7^{\text {th }}$ edition) :

Seniari, N.M., Supriyatna, Natsir, A., Adnyani, I.A.S., Nababan, S., \& Dharma, B.W. (2021). Pengenalan Dasar-Dasar Perencanaan Instalasi Proteksi Petir Pada Gedung 
Bertingkat di SMAN 8 Mataram. Abdi Insani, 8 (3), 352-358. http://doi.org/10.29303/abdiinsani.v8i3.436

\section{PENDAHULUAN}

Kurikulum Sekolah Menengah Atas (SMA) umumya memuat keterampilan praktis yang relative lebih kecil dibandingkan dengan kurikulum Sekolah Menengah Kejuruan (SMK). Sedangkan keterampilan khusus juga diperlukan oleh siswa SMA untuk membuka lapangan kerja mandiri. Mengingat tidak semua tamatan siswa SMA melanjutkan ke jenjang pendidikan yang lebih tinggi. Untuk itu team Pengabdian Kepada Masyarakat (PKM) Universitas Matram berusaha memberi keterampilan tambahan kepada siswa. Keterampilan ini bersifat spesifik, tidak terdapat dalam kurikulum SMA. Pemaparan materi dan pelatihan hanya diberikan konsep-konsep dasar perencanaan, yang nantinya bisa dikembangkan dan di latih secara mandiri.

Seniari \& Hadiyanti (2012), membahas tentang tegangan induksi yang diterima di sekitar titik sambaran petir. Dalam penelitian ini yang diskenariokan tersambar petir adalah gedung Rektorat Unram. Selanjutnya dihitung berapa besar tegangan induksi yang diterima gedung-gedung disekitar titik sambaran petir. Hasil menunjukkan bahwa pada jarak diatas $650 \mathrm{~m}$ dari titik sambaran, didapat medan listrik, medan magnet dan tegangan induksi yang aman untuk peralatan elektronik dan mahluk hidup.

Seniari et al., (2020), pelatihan untuk pemuda Gomong, yaitu memberi memaparkan tentang bagaimana cara memberi perlindungan pada suatu gedun dan perlindungan pada objek disekitar titik sambaran petir. Perlindungan dari sambaran petir menggunakan system proteksi eksternal, Peserta pelatihan diperkenalkan dengan peralatan dan pemasangan instalasi proteksi petir. Pemutaran videovidio terkait, sangat bermanfaat untuk menambah pengetahuan peserta. Pemasangan instalasi proteksi petir pada gedung tidak dapat melakukan perlindungan secara menyeluruh, tetapi mampu meminimalisir kerusakan fisik gedung dan mampu melindungi objek disekitar titik sambaran.

Sutrisna et al., (2017), membahas besarnya medan listrik $(E)$, medan magnet $(H)$ dan tegangan induksi $\left(V_{\text {ind }}\right)$ di sekitar titik sambaran. Diskenariokan gedung yang di sambar petir adalah Gedung STAHN Gde Pudja Mataram. Medan listrik, medan magnet dan tegangan induksi diamati pada Gardu Hubung Gomong Mataram yang berjarak $300 \mathrm{~m}$ dari titik sambaran. Hasil menunjukkan Gardu Hubung Gomong belum aman dari tegangan induksi yang dibangkitkan oleh sambaran petir di gedung STAHN Gde Pudja/

Seniari et al., (2021), membahas pengenalan Instalasi Petir Pada Gedung di SMAN 8 Mataram. Disampaikan bahwa kebutuhan instalasi petir merupakan tanggung jawab bersama, untuk meminimalisir kerugian material dan immaterial, melindungi gedung, isi gedung dan objek disekitar gedung. Wacana ini tertuang dalam peraturan pemerintah (PP) no. 36 tahun 2005 dan Undang-undang no. 28 tahun 2002. Kebutuhan akan instalasi proteksi petir merupakan suatu keharusan untuk memberi keamanan bersama. Keterampilan perencanaan pemasangan instalasi proteksi petir sangat menentukan hasil perlindungan yang optimal.

Suhartanto (2016), menentukan area gedung Teknik Elektro Undip yang terlindungi. Penelitian ini juga melakukan evaluasi system proteksi petir agar didapatkan perlindungan gedung yang optimal. Evaluasi system proteksi perlu dilakukan sehubungan dengan dibangunnya menara Base Transceiver Station (BTS) PT. Telkom.

Zainullah (2009), menentukan area gedung Rektorat Unram yang terlindungi dengan skenaro menerapkan metode jala, sudut proteksi dan bola bergulir. Hasil perencanaanya dengan skenario sudut perlindungan, mampu memberikan perlindungan pada gedung, dengan delapan (8) jumlah 
down koncuktor. Dengan menggunakan delapan down conductor, dapat menurunkan tegangan induksi, sehingga mampu menurunkan resiko kerusakan peralatan elektronik dan meningkatkan perlindungan terhadap nyawa mahluk hidup di sekitar titik sambaran petir.

\section{METODE KEGIATAN}

Kegiatan berlangsung tiga tahap yaitu tahap kunjungan dan perkenalan dengan kepala sekolah dan bagian HUMAS SMAN 8 Mataram. Pertemuan pertama menyampaikan maksud dan tujuan kunjungan ke sekolah, mengidentifikasi permasalahan dan menawarkan solusi melalui memberikan pelatihan. Untuk menentukan jadwal kegiatan, jumlah peserta, keperluan fasilitas dan sebagainya dikomunikasikan melalui whatsapp dengan pihak pengelola sekolah. Peserta pelatihan disepakati adalah wakil dari siswa kelas $\mathrm{X}, \mathrm{XI}, \mathrm{XII}$ dan perwakilan OSIS.

Pertemuan kedua adalah penyampaian materi pelatihan, berlangsung selama 4 jam dari jam 08.00 -12.00. Sebelum pemaparan materi, peserta di berikan kuisioner, dan kuisioner yang sama juga diberikan setelah pelatihan. Materi pelatihan dan peragaan alat instalasi petir disampaikan dengan ceramah, diskusi, tanya jawab dan pemutaran video-vidio terkait.. Akhir penyampaian materi, siswa diajak berlatih dasar menentukan kebutuhan bahan instalasi, dan menentukan titik-titik perlindungan melalui penempatan finial, down conductor dan grounding. Untuk berlatih lebih lanjut, siswa diberikan beberapa gambar gedung dengan bentuk dan dimensi yang bervariasi, dikerjakan dengan berkelompok di luar jam sekolah. Peserta juga diberikan materi-materi terkait, baik hasil penelitian, jurnal-jurnal, artikel terkait dan brousur-brousur perkembangan alat dan bahan instalasi petir.

Pertemuan ketiga adalah mengevaluasi hasil perencanaan instalasi yang telah dikerjakan oleh siswa. Peserta yang melaksanakan tugas perencanaan pemasangan instalasi petir secara mandiri adalah 5 dari 6 kelompok yang ada. Dalam pertemuan ini dilakukan secara bergilir untuk mengurangi kerumunan dan untuk menyesuaikan waktu belajar siswa di kelas.

\section{HASIL DAN PEMBAHASAN}

Pelaksanaan kegiatan pengabdian kepada masyarakat (PKM) di SMAN 8 Mataram berlangsung dengan lancar. Tempat beserta fasilitas pendukung memadai, peserta semua hadir tepat waktu dan mengikuti kegiatan sampai selesai. Secara kualitatif keberhasilan dan semangat siswa dalam mengikuti kegiatan dapat terlihat dari semangat mengikuti kegiatan, melakukan diskusi dan tanya jawab sangat kritis. Peserta mengikuti pemaparan materi dengan seksama, mengikuti kegiatan sampai selesai dan berlatih merencaakan instalasi petir dengan bersungguh-sungguh.

Pelatihan diawali menjelaskan tentang konsep terjadinya petir. Selanjutnya dijelaskan tinjauan teknis sambaran petir yang dapat membangkitakan medan listrik (E) dan medan magnet $(H)$ (Hasse, 1992). Medan listrik dan medan magnet muncul bersamaan disekitar titik sambaran, karena adanya muatan petir yang bergerak pada down konduktor (konduktor yang dialiri arus petir). Kedua medan ini selain dapat membahayakan mahluk hidup disekitar titik sambaran, medan listrik $(E)$ dan medan magnet $(H)$ juga membangkitkan tegangan induksi $\left(V_{\text {ind }}\right)$, yang mana tegangan induksi ini berpotensi merusak peralatan elektronik, dan jaringan data di sekitar titik sambaran (Seniari \& Dharma, 2020a) Jadi peserta pelatihan diberikan pengetahuan tentang cara melindungi dan meminimalisir kerugian dampak sambaran petir langsung dan dampak sambaran petir tidak langsung (objek disekitar titik sambaran) (Seniari \& Dharma, 2020b). Bila objek yang disambar petir sudah menggunakan sistem proteksi petir, maka objek tersebut tidak akan mengalami kerusakan fisik. Tetapi objek yang disambar langsung dan objek disekitar titik sambaran tidak bisa terhindar dari tegangan yang diinduksikan oleh medan listrik $(E)$ dan medan magnet $(H)$ (Eritech, 2009). 
Standar Nasional Indonesia (SNI) 03-7015-2004 yang membahas tentang sistem proteksi pada gedung, digunakan sebagai referensi dalam perencanaan. Dalam SNI tersebut juga dibahas tentang metode perlindungan yaitu metode jala, metode sudut perlindungan dan metode bola bergulir.

Berikutnya tutor memperagakan penyambungan dan pemasangan instalasi sistem proteksi petir (Seniari et al., 2020). Siswa secara berkelompok juga melakukan penyambungan-penyambungan diawasi oleh tutor dan diberi pengarahan cara melakukan sambungan-sambungan yang benar. Sambungan yang benar-benar tersambung sangat penting, agar arus petir yang mengalir dari finial ke down condukor dan menuju grounding, mengalir dengan lancar.

Pelatihan perencanaan system proteksi petir, dikerjakan secara berkelompok. Peserta diberikan gambar gedung dengan dimensi dan bentuk atap yang berbeda. Berdasarkan (SNI 03-7015-2004), peserta dilatih menentukan kebutuhan bahan instalasi, menentukan titik-titik perlindungan untuk mendapatkan area perlindungan yang optimal, dan untuk meminimalisir tegangan induksi yang diterima objek disekitar titik sambaran (Seniari, et al., 2020) (Seniari et al., 2020).

Secara kuantitatif, penilaian pelaksanaan pelatihan terukur dari kuisioner yang diisi oleh peserta sebelum dan sesudah kegiatan pelatihan dilakukan. Kuisioner berisikan pertayaan praktis yang mewakili pengetahuan siswa tentang sistem proteksi petir pada gedung, kebutuhan alat dan bahan serta langkah-langkah perencanaan. Hasil kuisioner setelah kegiatan pelatihan untuk menilai kemajuan yang didapat peserta setelah pelatihan berlangsung. Gambar 1 menunjukkan keaktifan siswa berdiskusi dan tanya jawab. Gambar 2 menunjukan pembukaan kegiatan oleh bagian HUMAS SMAN 8 Mataram dan pemaparan materi.

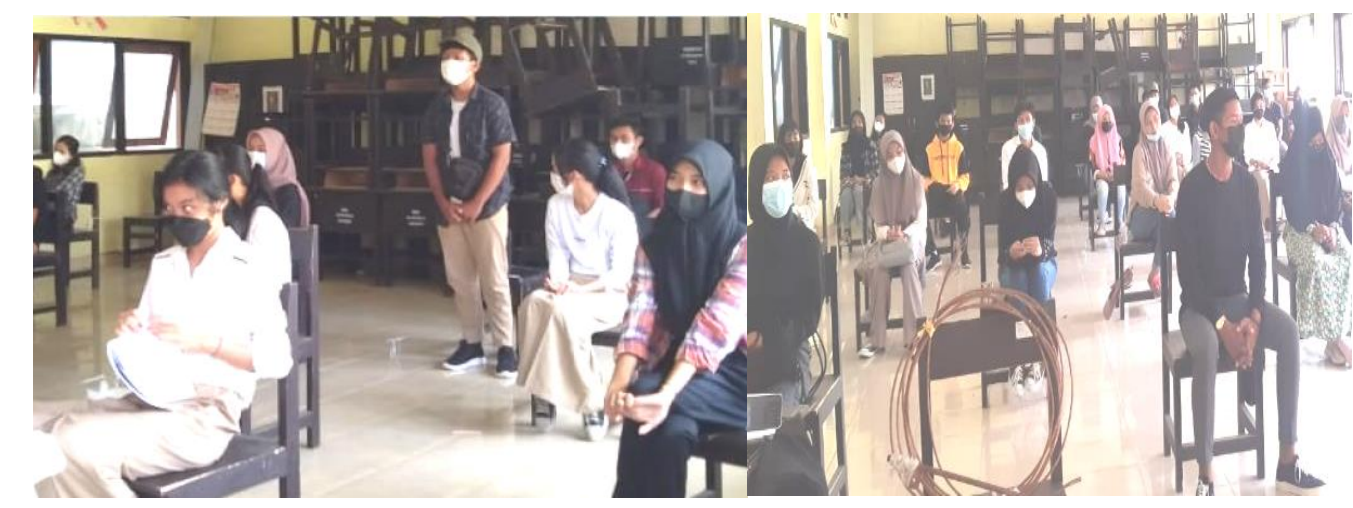

Gambar 1. Peserta pelatihan aktif melakukan tanya jawab dan berdiskusi

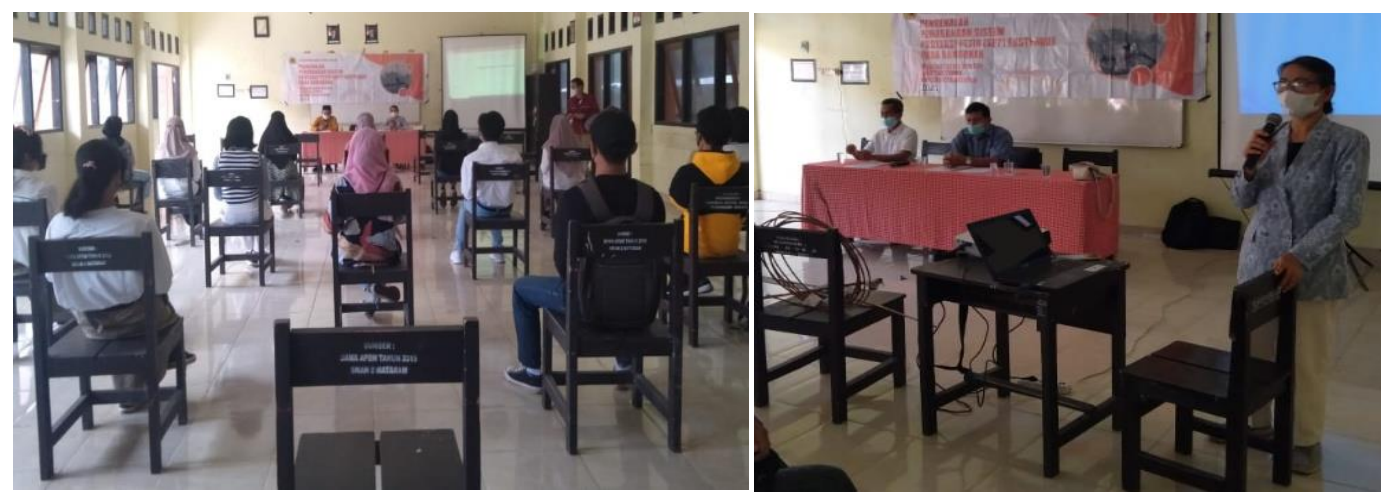

Gambar 2. Pembukaan oleh bagian HUMAS SMAN 8 Mataram dan pemaparan materi

Berikut adalah kuisioner beserta jawaban siswa sebelum dan sesudah kegiatan berlangsung. 
Tabel 1. Hasil isian kuisioner oleh peserta

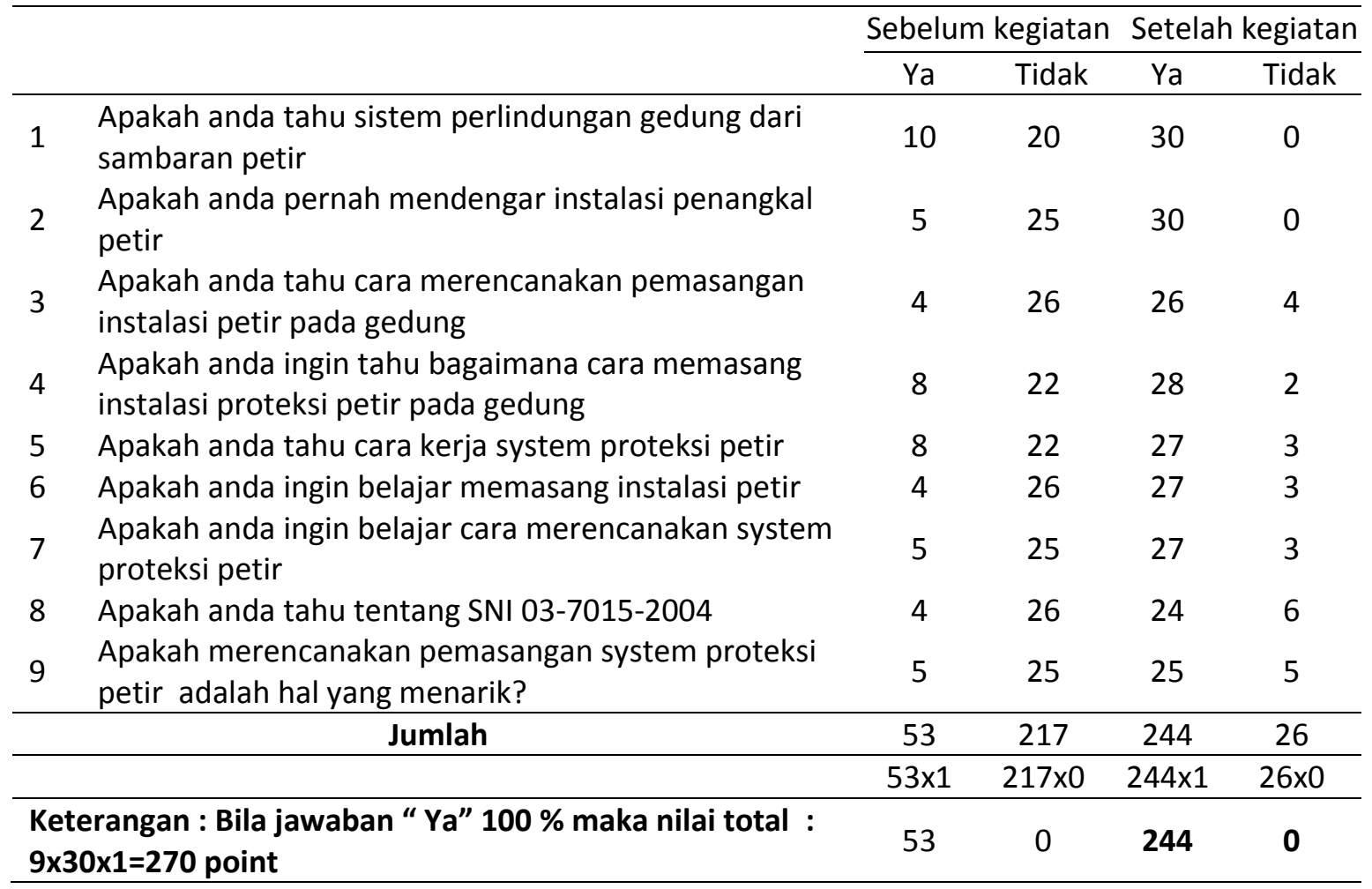

Keterangan :

- Jumlah responden 30 orang

- Jumlah pertanyaan 9

- Responden menjawab "Ya" point 1 (satu)

- Responden menjawab "Tidak" point $\mathbf{0}$ (nol)

Jawaban kuisioner mampu memberikan informasi tentang pengetahuan, pemahaman dan keterampilan siswa tentang sistem proteksi petir sebelum dan sesudah pelatihan. Selain itu hasil jawaban kuisioner yang dikonversi menjadi angka, dapat mengindikasikan kemajuan pengetahuan dan keterampilan siswa setelah pelatihan. Kemajuan pengetahuan dan keterampilan siswa dihitung dengan mengurangi nilai setelah pelatihan dengan nilai sebelum pelatihan.

Persentase keberhasilan kegiatan PKM secara kuantitatif dapat dihitung sebagai berikut :

- Hasil jawaban 'Ya' sebelum kegiatan PKM. Jawaban ini menunjukkan kemampuan dan pengetahuan siswa sebelum pelatihan :

$\frac{53}{270} \times 100 \%=19,63 \%$

- Hasil jawaban 'Ya' sesudah kegiatan PKM. Jawaban ini menunjukkan kemampuan dan pengetahuan siswa setelah pelatihan.

244

$\frac{244}{270} x 100 \%=90,37 \%$

- Prosentase peningkatan prestasi yang diperoleh setelah kegiatan adalah :

$90,37 \%-19,63 \%=70,74 \%$

Nilai 70,74 \% ini menunjukkan bahwa kegiatan PKM bermanfaat dan berhasil meningkatkan pengetahuan dan keterampilan siswa sebesar 70,74\%. 


\section{KESIMPULAN DAN SARAN}

Kesimpulan yang dapat diambil melalaui kegiatan ini adalah :

1. Kegiatan pelatihan ini dapat meningkatkan pengetahuan dan pengalaman siswa dalam perencanaan instalasi sistem proteksi petir eksternal.

2. Peningkatan pengetahuan, keterampilan dan pengalaman siswa meningkat $70,74 \%$.

Saran untuk meningkatkan hasil pengabdian kepada masyarakat, dan untuk menjalin kerja sama yang baik antara Perguruan Tinggi dengan pihak sekolah, perlu dilakukan kegiatan yang terjadwal secara reguler, dengan fasilitas, sarana dan prasarana yang lebih baik dan lebih lengkap.

\section{UCAPAN TERIMA KASIH}

Terimakasih di sampaikan kepada civitas Akademik Unram bapak ibu guru, serta siswa/i SMAN 8 Mataram. Terimakasih kepada teman-teman dan adik-adik mahasiswa atas dukungannya sehingga kegiatan ini bisa berjalan dengan lancar dan bermanfaat.

\section{DAFTAR PUSTAKA}

Eritech. (2009). Lightning Protection Handbook Designing To The IEC 62305 Series Of Lightning Protection Standards. Solon (US) : ERICO International Corporation.

Hasse, P. (1992). Overvoltage Protection of Low Voltage System. England : linstitution of electrical engineers.

Seniari, N. M., \& Dharma, B. W. (2020a). Penyuluhan Cara Mengurangi Bahaya Radiasi Gelombang Elektromagnetik Pada Kesehatan Di Kelurahan Pagutan Barat Mataram. Jurnal Bakti Nusa, 1(2), 32-38. https://doi.org/https://doi.org/10.29303/baktinusa.v2i1:April 2021.19

Seniari, N. M., \& Dharma, B. W. (2020b). Penyuluhan Bahaya Radiasi Gelombang Elektromagnetik pada Organ Tubuh Mahluk Hidup di Kelurahan Pagutan Barat Mataram. Prosiding Pepadu, 230-235. https://jurnal.lppm.unram.ac.id/index.php/prosidingpepadu/issue/view/6

Seniari, N. M., Ginarsa, I. M., Citarsa, I. B. F., Supriyatna, \& Adnyani, I. A. S. (2020). Electric and Magnetic Field Around The Tower Due To Lightning-Strikeusing lightning Current Simulation. Proceedings ICST 2020, 540-551. http://procceding.unram.ac.id/index.php/icst/index

Seniari, N. M., \& Hadiyanti, A. (2012). Studi Kopling Induksi Pada Peralatan Listrik di Sekitar Gedung Rektorat Unram Akibat Sambaran Petir. Prosiding Seminar Nasional, Teknik Elektro Dan Informatika Dalam Pengembangan Teknologi Berkelanjutan.

Seniari, N. M., Supriyatna, Natsir, A., Nababan, S., \& Adnyani, I. A. S. (2021). Pengenalan Instalasi Petir Pada Gedung di SMAN 8 Mataram. Jurnal Karya Pengabdian, 3(2), 106-111. http://jkp.unram.ac.id/index.php/JKP

Seniari, N. M., Supriyatna, Natsir, A., Nababan, S., Rosmaliati, \& Adnyani, I. A. S. (2020). Pengenalan Pemasangan Sistem Proteksi Petir (SPP) Eksternal Pada Gedung di Kota Mataram. Prosiding Seminar Nasional Hasil Pengabdian Kepada Masyarakat Universitas Negeri Makassar, 487-492. https://ojs.unm.ac.id/semn

Seniari, N. M., Supriyatna, Natsir, A., Nababan, S., Rosmaliati, \& S, A. I. A. (2020). Pengenalan Pemasangan Sistem Proteksi Petir (SPP) Eksternal Rumah Tangga Bagi Siswa SMAN 4 Mataram. Mataram (ID) : LPPM Universitas Mataram.

SNI. (2004). Standar Nasional Indonesia 03-7015-2004, Sistem Proteksi Petir pada Gedung.

Suhartanto, T. (2016). Penentuan Kebutuhan proteksi Petir pada Gedung Teknik Elektro UNDIP Dengan Adanya Bangunan Menara Base Transceiver Station. Universitas Diponogoro.

Sutrisna, I. W., Seniari, N. M., \& Ginarsa, I. M. (2017). Analisis Tegangan Lebih Induksi Di Sekitar Down Conductor Yang Terinjeksi Arus Petir (Studi Kasus Gedung STAHN Gde Pudja Mataram dan Gardu Hubung Gomong). Jurnal Dielektrika, 4(1), 1-9.

Zainullah. (2009). Penerapan Metode Jala, Sudut Proteksi dan Bola Bergulir pada Sistem Proteksi Eksternal Yang Di Aplikasikan pada Gedung Rektorat Unram. Universitas Mataram. 